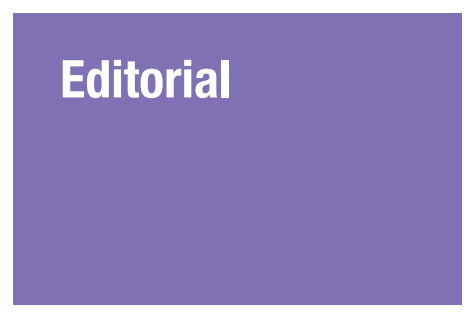

Submitted: 4 Aug 2016 Accepted: 15 Oct 2016 Online: 7 Dec 2016

\section{Can We Improve Training for Health Professionals to Sustain Local Health Development?}

\section{Stephen KING}

\author{
Consultant in Education and Training, \\ SEAMEO-TROPMED Network, \\ 420/6 Ratchawithi Road, \\ Bangkok 10400 , \\ Thailand
}

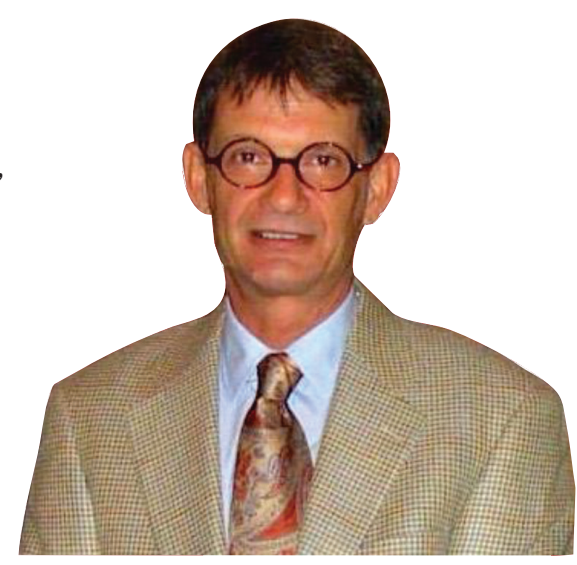

To cite this article: King S. Can we improve training for health professionals to sustain local health development? Malays J Med Sci. 2016;23(6):1-6. http://dx.doi.org/10.21315/mjms2016.23.6.1.

To link to this article: http://dx.doi.org/10.21315/mjms2016.23.6.1

\begin{abstract}
Can we improve training for health professionals? We explore specific variables that need to be accounted for to achieve sustainable local health development through training. A problembased approach with appreciation of the need for making changes is suggested as the only authentic basis for training.
\end{abstract}

Keywords: curriculum, health professionals, problem-based learning, service learning, Southeast Asia, sustainable health development, team-based learning, training, universities

\section{Do We Have a Problem with Providing Training for Health Professionals?}

Do we have a problem? They say that the 'first step in fixing a problem is admitting you have one' (1). However, 'admission' infers that there is some wilful ignorance; a less than desirable motive. What if there is nothing of the sort, but simply and plainly 'ignorance'?

Sustainable social health development requires more than technical knowledge and skills training alone. Health professionalsproviders, managers, and administrators-need to respond to their individual challenges at specific times and in particular places. It is no longer appropriate to focus on a single issue; wickedly complex problems are the primary tasks of these professionals.

Health professionals should have access to quality training for them to fulfil their respective roles and functions for sustainable development, especially at local levels. Unfortunately, this is often not the case, or at the very least, we could certainly make improvements. Here, we will address some of these problems with the hopes that it will be a contribution to the discussion of how to improve training.

\section{Topics versus Subjects}

Curricula in most training courses are organised according to topics (Integrated Vector Management, Collecting and Managing Data in the Field, Demonstration of Vector Control Methods, Emergency Response Planning, Policy and Guideline Development, Management of Logistics and Supplies, and so forth). However, most universities organise their courses according to subjects (Biostatistics, Epidemiology, Research Methods, 
Environmental Health, Health Economics, and so forth). While there may be some apparent overlap, the university-based, subjects tend to be more theoretical, while the training courses are mostly practical.

Resource persons, putative 'experts,' who are invited as instructors could reflect these differing worldviews, which may lead to some differences in the approaches to teaching. University-based lecturers are more familiar with a classroom setting and possibly research ('publish or perish'). Others invited to act as resource persons are usually from on-the-ground organisations, agencies, or ministries. These instructors, for the most part, bring practical experience and knowledge.

We have found that these differences are important and could result in much conflict among the instructors, but also confusion among those attending as participants. It is essential for the course organising committee to, first, determine which teaching-learning methods will be adopted for the entire course; second, to communicate these methods to the resource persons; third, to have facilitators to ensure consistency in each session and throughout the course; and, finally to introduce these methods to the participants, so that they will be comfortable with any novel approaches.

\section{Teacher-versus Student-centred}

Recent changes in pedagogy have shifted focus away from the teacher to the student (2). It should be noted; however, that these changes are mostly in pre-university settings. Universities appear to be reluctant, with significant exceptions, to adopt any of these changes (37). It could be argued that in Southeast Asia, this problem is probably more so as a result of a tendency for national sociocultural norms to creep into university systems: nepotism, patronage, and dodgy ethics.

These student-centred approaches (8-9) include problem-based learning (10) (Figure 1), team-based learning (11) (Figure 2a,b), service learning (12). These approaches which hand over more control to the students, in our experience, fail miserably in university settings, even though some initiatives are made; over time, academic courses will revert to the familiar. Lecturers are especially afraid of being challenged by students, so interactive or participatory approaches rarely happen. If there is hope, it remains with international agencies and ministries that organise training courses.

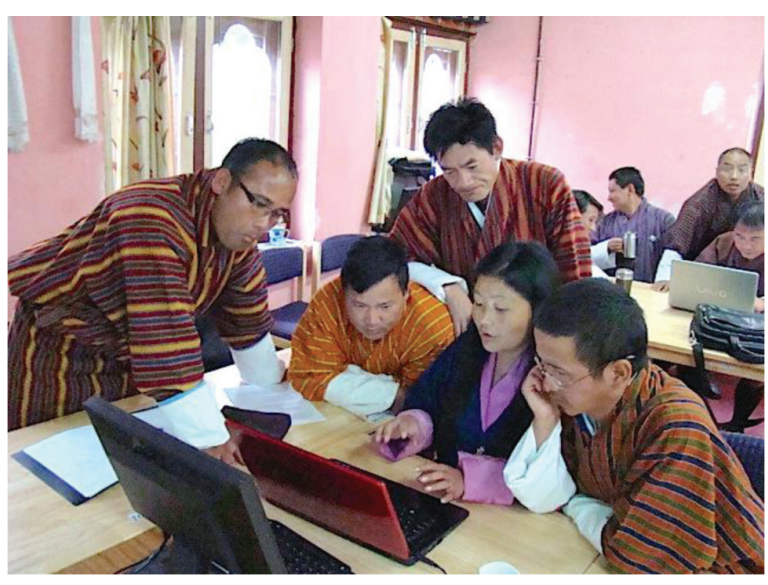

Figure 1. BPH students work primarily in small groups in class at RIHS. (Photo credit: Author)

The Bachelor of Public Health (Royal Institute of Health Sciences, Bhutan) was an opportunity for the inclusion of a number of these student-centred methods. This programme was an upgradation course for previous graduates of RIHS (Health Assistant certificate). The programme lasted four semesters; the final semester being almost entirely in the field as 3-student groups. The first half of the semester (approximately two months) involved the students doing situational analyses of, for example, an individual handicapped patient, a Basic Health Unit (BHU), district-wide health evaluation, and hospital information system.

After presentations of the group results, the students selected one of the findings for an individual project that would last for the remainder of the semester. They were assigned to plan, implement, and evaluate their projects, without any resources provided other than what they were able to mobilise themselves locally (Figure 3-4). By all accounts and their own evaluations, this was highly successful as a learning experience.

\section{Curriculum Design}

Lecturers or degree-holding officials, who base their ideas of education on their previous degrees (the more senior, the more dated) should not be allowed anywhere near the curriculum design process, except perhaps to contribute their specific area of expertise. They should not be involved in organising the teaching-learning activities. This may well be contentious, as subject experts tend to equate their professional expertise with how they acquired it and impose 


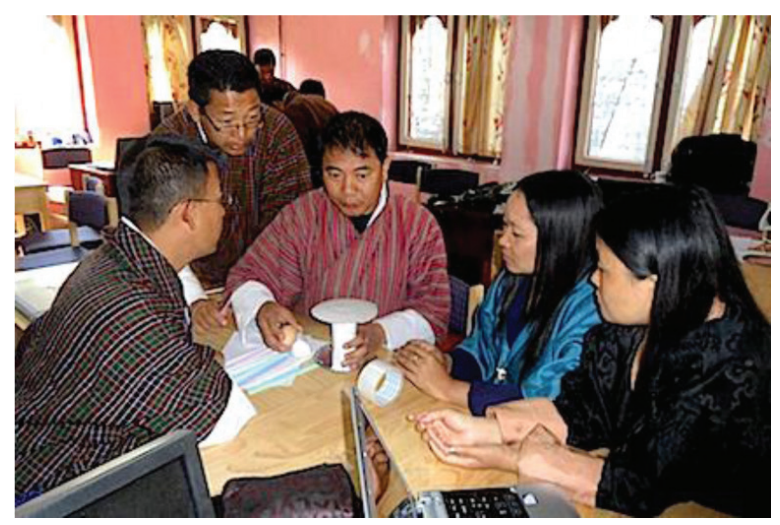

Figure 2a. BPH students work in teams on the management of group dynamics and communication. The aim of the exercise was to construct (with the same materials provided) a device that would ensure that a raw egg survived a drop of 1 storey. (Photo credit: Matthias Pullmann)

those methods with some authority. Curriculum design should be allocated to those with experience, especially in developing training programmes; with subject experts providing their contribution.

Every subject expert feels that his or her subject should have priority, and the ensuing disagreements can be quite acrimonious. This is why it is important to define the purpose of the course, the target audience, and what the learning objectives are. These learning objectives

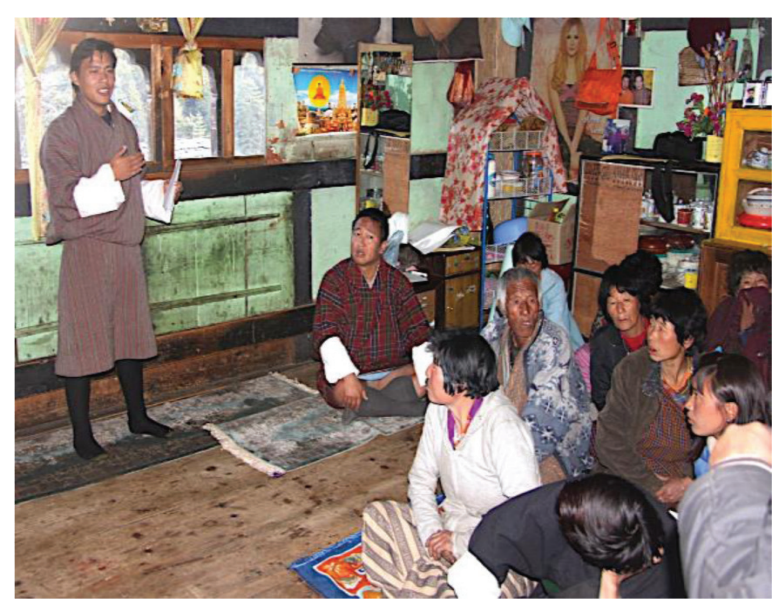

Figure 3a. Community Mobilisation. An indigent villager had been identified in the previous analysis phase. This student mobilised the community to address her needs.

(Photo credit: Gang Dorji)
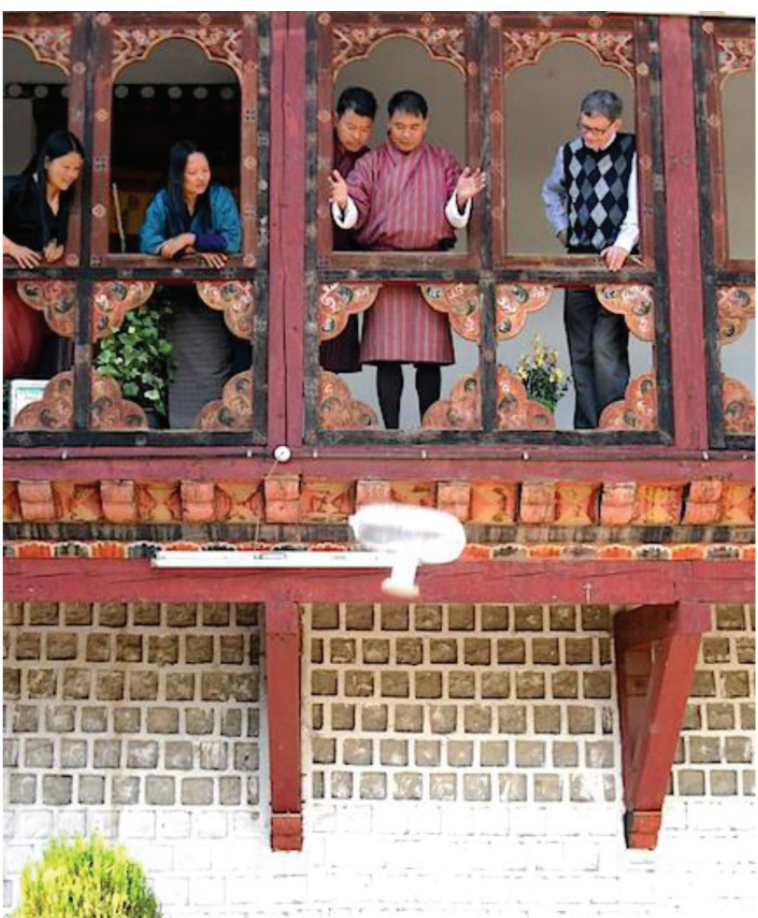

Figure 2b. The test: success rate was 50\%.

(Photo credit: Matthias Pullmann)

should be consistent with the teaching-learning activities as well as the evaluation (11).

A common problem, reminiscent of university courses, is the so-called 'silo' effect, whereby subject material (with a Table of Contents arrangement) dictates the training course material. It is essential to focus on what

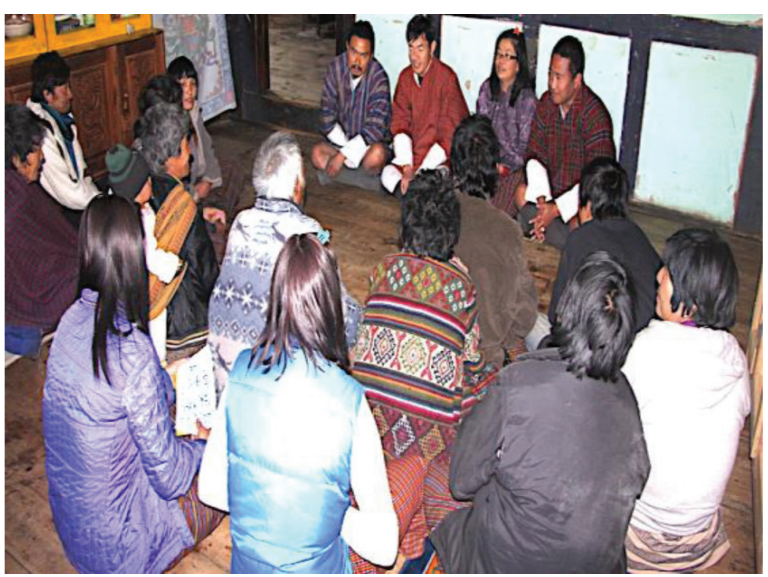

Figure 3b. Committee Formation. The committee that resulted from these efforts arrange for her room renovation, monitoring, acquiring supplies, and setting up a bank account to handle the finances. (Photo credit: Gang Dorji) 


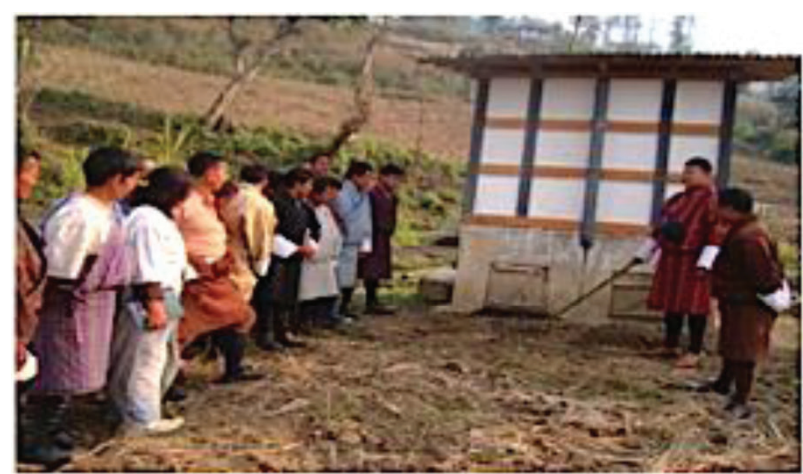

Picture above: Health education proper use of on Eco-SAN toilet

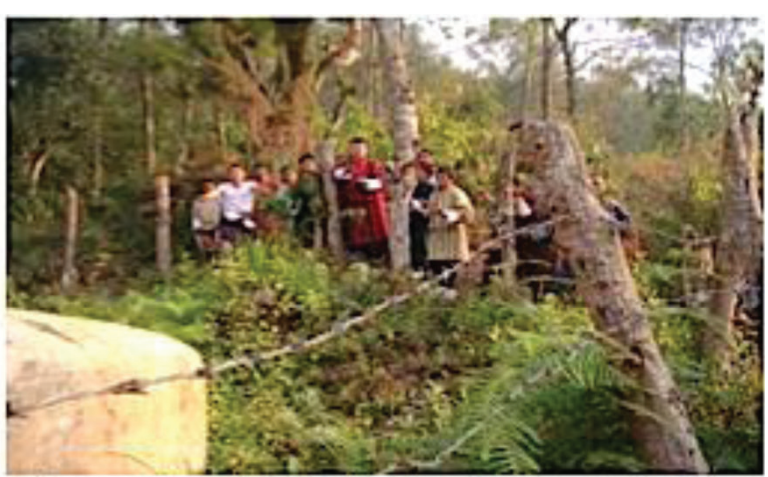

Picture above: Briefing on how to take care of reservoir tank

Figure 4. One student wanted to strengthen the role of local government to control typhoid. His efforts focussed on latrines and water supply, as well as hand washing and personal hygiene. (Photo credit: Kinley T)

the students actually learn to do, rather then what they know. Knowledge can easily change and vary according to location, and students should learn how to obtain more up-to-date and situation-specific information, but attitudes and skills should be the primary outcome of training.

\section{Training Venues}

The locations where training course are held are either training centres or more often hotels, as a large number of participants can easily necessitate the later venue. Experienced training organisers will know that they have to give very specific instructions to any host, if they want to avoid changing all the arrangements of furniture. If a hotel Food and Beverage department learns that training is to take place, they will line up chairs, perhaps with desks as well, facing front like good little school children; facing the lectern of the ever-changing speaker. Any group work with interactive dialogue is doomed. Large round tables seem to be the best arrangement for interaction.

The timetable is also vulnerable to imposing on the learning process: morning and afternoon sessions, each with a set time period will make administrators happy, but it is antithetical to good learning, which should have flexibility built in.

Tea breaks are also mandated (at 3 o'clock for 15 minutes). Who says so? Why not just place refreshments out during the afternoon period and let the participants decide for themselves when to take a break? Do they really need catering staff to pour the coffee; what are they afraid that someone may steal a teaspoon?
This is just an example of how training course timetables can smother participant enthusiasm.

\section{Premature Evaluation}

Kirkpatrick (13) has defined four levels of course evaluation: Level 1 (How did the participants react?), Level 2 (What did they learn?), Level 3 (How did they apply what they learned in their work?), and Level 4 (What was the impact of those applications?). Most training course will include the first two levels: satisfaction surveys as well as pre-and posttesting (mostly basic knowledge). Occasionally, there will be external evaluations, sometimes mandated by the funding agency, but these seldom go to the second two levels.

The latter two levels are not assessed, as it is simply too expensive or complicated to do follow up, or, frankly, organisers do not care. Even funding agencies may be more concerned that the attendees all passed, the budget was well spent, and they receive great credit.

The problem with Levels 3 and 4 is that they necessarily involve change; change in the behaviours of the individuals, and changes that result from their actions (which, admittedly can be complicated with all sorts of confounding variables). Change is an awkward phenomenon.

Any change would necessarily involve a process that includes a decline in performance or outputs by virtue of unfamiliarity, fear, or discomfort, followed by increasing performance until (hopefully) a higher level results (14). How long does the period of chaos last, and how long does it take to reach improved levels? It depends. 
However, if an evaluation is conducted during the necessary chaotic period, this would show only failure, as it was premature and not understanding the necessity of the change process. It is surprising how many organisations mandate a certain period to do evaluations not taking this into account. Perhaps this is why they do not do Levels 3 and 4 evaluations; it messes up their happiness.

\section{Are We Failing to Learn or Learning to Fail}

Can we improve training for health professionals? One answer could be that it would be difficult to achieve if we do not make significant changes in the institutional culture of training programmes. Any problem requires a careful, honest analysis of all the variables involved. We have just touched on a few of them above. Why can we not make improvements?

Sustainable local health development suggests that a problem-solving approach needs to be adopted through cycles of change. If we do not emphasise this in our training courses, then we are unlikely to have a significant impact.

\section{Acknowledgements}

This article reflects our 35 years of experience, together with support of colleagues, in developing curricula for degree programs [Community and Family Case Study, Medical School, Universiti Sains Malaysia; Master of Public Health (international and Learning-atthe-Workplace programs), College of Public Health, Chulalongkorn University, Thailand; Bachelor of Public Health, Royal Institute of Health Sciences, Bhutan]. We have also been curriculum consultant and instructor for short-course training programs (Canada-Asia Partnership; ACTMalaria; Bureau of Vectorborne Diseases, Ministry of Public Health, Thailand; Asian Institute of Technology, Bangkok; Asia Disaster Prevention Center, Bangkok; and Field Epidemiology Training Program, Bhutan). Special appreciation is due to all of the students and participants of these courses for their enthusiastic contributions.

\section{Conflict of Interest}

None.

\section{Funds}

None.

\section{Correspondence}

Dr. Stephen King

DrPH Public Health (University of Hawaii),

MMedSci Community Health (University of

Nottingham),

BSc Experimental Psychology (University of Sussex), CEGEP Biological Sciences (McGill University)

SEAMEO-TROPMED Network,

420/6 Ratchawithi Road,

Bangkok 10400, Thailand

Tel: +66-81-6299304; +66-2-3549179

E-mail: sking51@yahoo.com

\section{References}

1. Oswald D. First step in fixing a problem is admitting you have one. (cited 2016 Oct 17). Available from: http://recruitingdailyadvisor. blr.com/2016/09/first-step-fixing-problemadmitting-one/\#

2. Robinson K, Aronica L. Creative schools: the grassroots revolution that's transforming education. London: Penguin; 2016.

3. The Open University. UK universities are missing out on teaching innovations. (cited 2016 Oct 16). Available from: https://www3.open.ac.uk/media/ fullstory.aspx?id=23826

4. BBC Active. Innovative teaching methods vs the traditional university lecture. (cited 2016 Oct 16). Available from: http://www. bbcactive.com/BBCActiveIdeasandResources/ Innovativeteachingmethodsvsthetraditional uni.aspx

5. High Level Group on the Modernisation of Higher Education. Report to the European Commission on new modes of learning and teaching in higher education. (cited 2016 Oct 16). Available from: http://ec.europa.eu/dgs/ education_culture/repository/education/library/ reports/modernisation-universities_en.pdf

6. Zhu, C. How innovative are schools in teaching and learning? A case study in Beijing and Hong Kong. Asia-Pac Educ Res (forthcoming). http:// dx.doi.org/10.1007/s40299-012-0006-4. 
7. Pham TT, Renshaw P. How to enable Asian teachers to empower students to adopt studentcentred learning. Aust $J$ Teach Educ 2013; 38(11): 65-85. http://dx.doi.org/10.14221/ajte. 2013v38n11.4.

8. Egan K. Leaning in depth: a simple innovation that can transform schooling. Chicago, IL: University of Chicago Press; 2011.

9. Weimar M. Learner-centered teaching: 5 key changes to practice. San Francisco, CA: JosseyBass; 2002.

10. Klatt B. The ultimate training workshop handbook: a comprehensive guide to leading successful workshops and successful training programs. New York City, NY: McGraw Hill Education; 1999.
11. Michaelson LK, Parmelee DX, McMahon KK, Levine RE, editors. Team-based learning for health professions education: a guide to using small groups for improving leaning. 1st ed. Sterling VA: Stylus Publishing; 2007.

12. Jacoby B and Associates. Service-learning in higher education: concepts and practices. San Francisco, CA: Jossey-Bass; 1996.

13. Kirkpatrick J, Kirkpatrick WK. The Kirkpatrick Four Levels ${ }^{\mathrm{TM}}$ : a fresh look after 50 years 19592009. Newnan, GA: Kirkpatrick Partners; 2009.

14. Karten, N. Changing how you manage and communicate change. Randolph, MA: Karten Associates; 2009. (cited 2016 Oct 12). Available from: https://conference.eurostarsoftwaretesting. com/wp-content/uploads/keynote_2.pdf 